\title{
Argon plasma coagulation before mechanical fragmentation of a large gastric persimmon bezoar: the woodworm technique
}

In February 2013, a 74-year-old man with a history of postprandial epigastric pain and nausea underwent esophagogastroduodenoscopy (EGD) at our institute. The patient was a farmer with a longstanding history of persimmon consumption. EGD showed the presence of an ovoid, tough mass with a smooth surface of dark green color in the stomach lumen, with a maximum diameter of about $8 \mathrm{~cm}$, suggestive of a persimmon bezoar ( $\mathbf{F i g . 1} \mathbf{a}$ ).

A 30-mm polypectomy snare (Captivator; Boston Scientific Corp., Natick, Massachusetts, USA) was closed around the bezoar edge and a pull and release movement was applied to obtain a saw-like effect while keeping the bezoar firmly against the endoscope ( $\bullet$ Fig. 1 b).

Despite these maneuvers, fragmentation failed. Therefore, a new argon plasma coagulation (APC) approach, which we have named the "woodworm technique," was utilized. A frontal 2.3-mm APC probe was used (VIO 300D with APC2; Erbe Elektromedizin, Tübingen, Germany) with a gas flow rate of $2.0 \mathrm{~L} / \mathrm{min}$, at a power setting of $50 \mathrm{~W}$. Mimicking woodworm behavior, the APC probe was advanced through the bezoar creating multiple tunnels in order to weaken the structure ( $\mathbf{F i g . 2}$ ). When snared again, the weakened bezoar was successfully ruptured. By repeating the APC-snare sequence, smaller fragments were obtained and crushed with a standard lithotripter to complete bezoar fragmentation ( Fig.3). Patient symptoms improved drastically in the following days.

Phytobezoars, the most common type of bezoar, are concretions of poorly digested fruit and vegetable fibers that are found in the alimentary tract $[1,2]$. A number of surgical, endoscopic, and pharmacological treatments with variable efficacy have been proposed $[3,4]$. This report describes a new and easy technique for the management of phytobezoars. After failure of standard endoscopic methods, and in order to avoid surgery, the APC "woodworm technique" may be used to create multiple tunnels that weaken the structure of the bezoar and facilitate mechanical fragmentation.
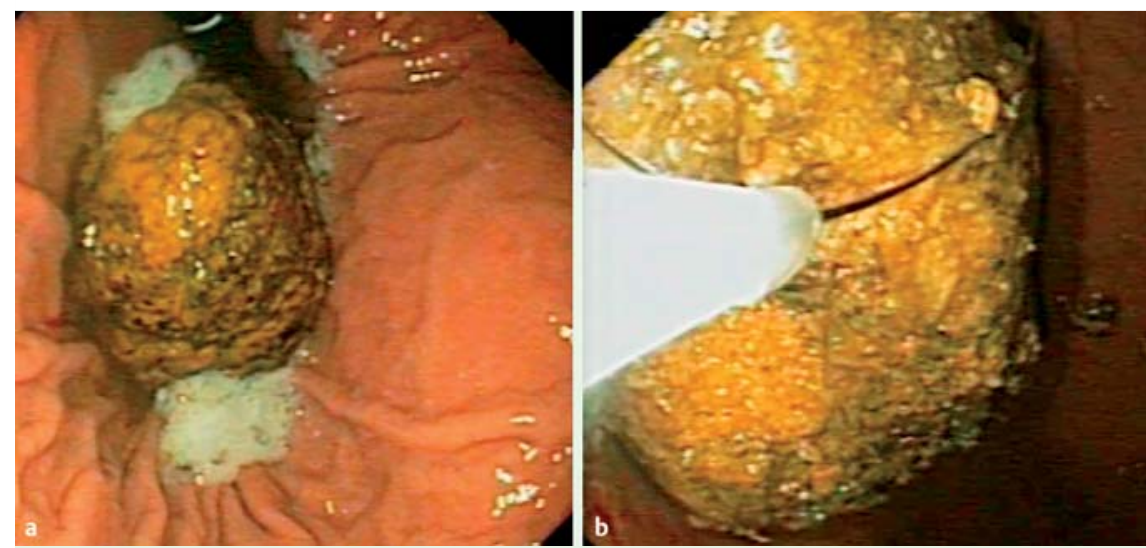

Fig. 1 Persimmon bezoar in the stomach. a Endoscopic appearance. b Removal was attempted using a polypectomy snare.
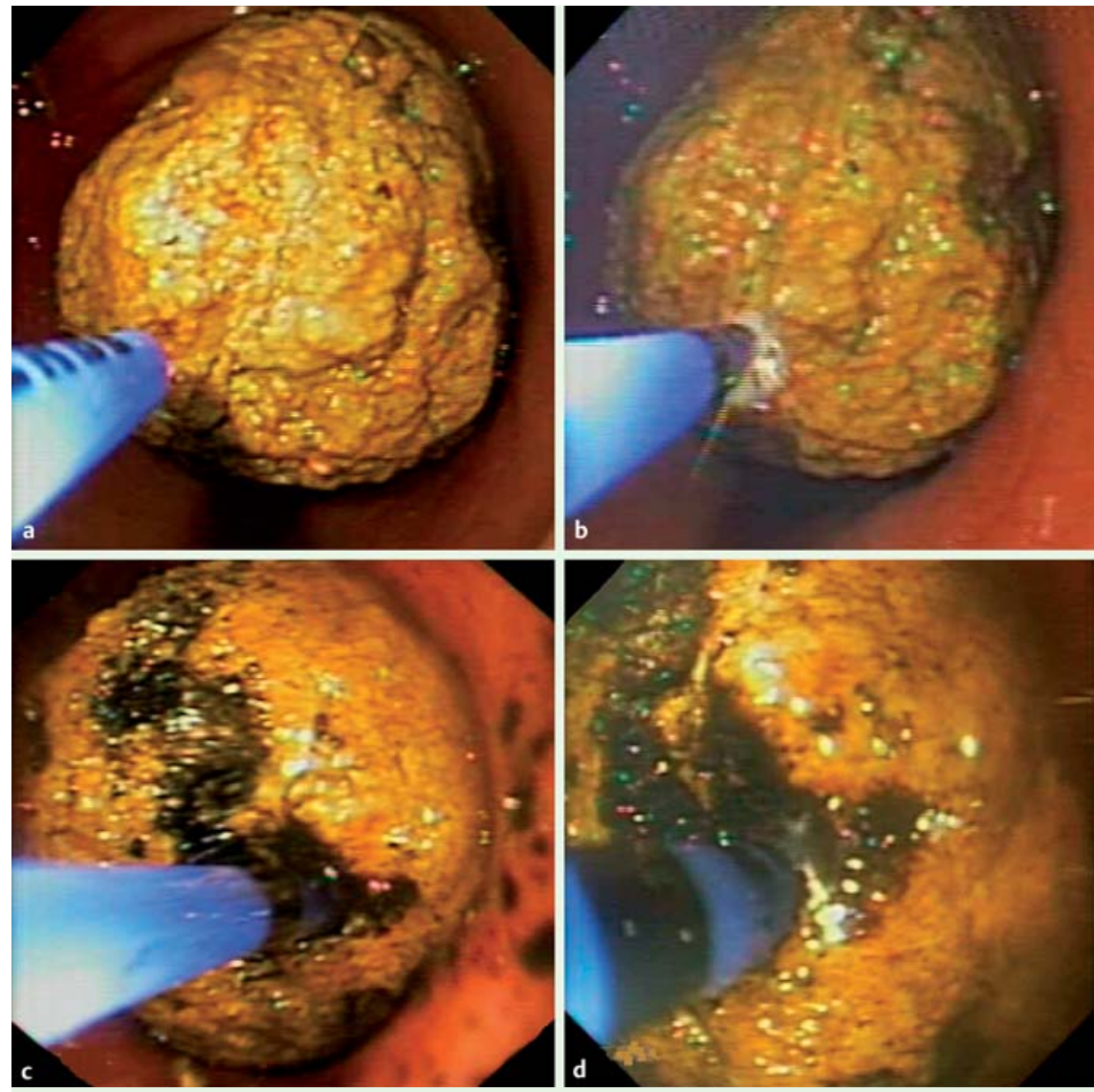

Fig. 2 Endoscopic view of the "woodworm technique." a The argon plasma coagulation probe. b Coagulation. c, d Tunnel creation.

Endoscopy_UCTN_Code_TTT_1AO_2AN

Competing interests: None 

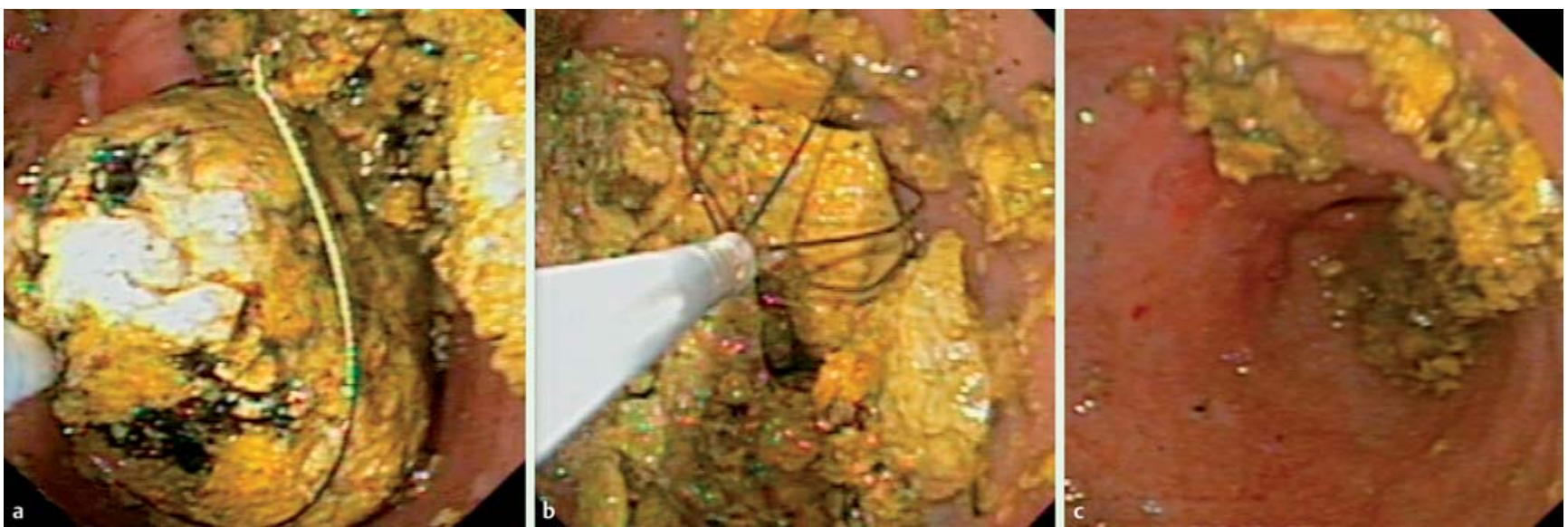

Fig. 3 Bezoar rupture and fragmentation. a The polypectomy snare. b Rupture using a lithotripter following the "woodworm technique." c Complete fragmentation of the bezoar.

\section{G. Curcio, A. Granata, N. Azzopardi, L. Barresi, I. Tarantino, M. Traina}

Gastroenterology and Endoscopy Unit, Mediterranean Institute for Transplantation and Advanced Specialized Therapies (ISMETT), Palermo, Italy

\section{References}

1 Teng H, Nawawi O, Ng K et al. Phytobezoar: an unusual cause of intestinal obstruction. Biomed Imaging Interv J 2005; 1: e4

2 Kim Y, Park BJ, Kim MJ et al. Biliary phytobezoar resulting in intestinal obstruction. World J Gastroenterol 2013; 19: 133-136

3 Gayà J, Barranco L, Llompart A et al. Persimmon bezoars: a successful combined therapy. Gastrointest Endosc 2002; 55: 581 583

4 Lee BJ, ParkJJ, Chun HJ et al. How good is cola for dissolution of gastric phytobezoars? World J Gastroenterol 2009; 15: 2265-2269

\section{Bibliography}

DOI http://dx.doi.org/

10.1055/s-0033-1344220

Endoscopy 2013; 45: E227-E228

(c) Georg Thieme Verlag KG

Stuttgart · New York

ISSN 0013-726X

\section{Corresponding author}

\section{G. Curcio, MD}

Gastroenterology and Endoscopy Unit ISMETT UPMC

Via Tricomi 1

Palermo 90127

Italy

Fax: +39-091-2192400

gcurcio@ismett.edu 